\title{
Dom e Carisma na economia: reflexões a partir do pensamento de Chiara Lubich
}

\section{Gitt and Charisma in the economy: reflections from the thought of Chiara Lubich}

\author{
Marcio Luiz Fernandes* \\ Cleiton Costa de Santana**
}

Resumo: O presente artigo versa sobre a busca de critérios e motivações econômicas que contrastem com a lógica instrumental predominante nos dias de hoje. O nosso percurso teórico partirá da distinção entre economia formal e substantiva, conforme enunciada por Karl Polanyi, passará pela crítica à lógica utilitarista, chegando à exigência do resgate de critérios em desuso, como o dom e a reciprocidade, presentes nos carismas. Aproximamo-nos, assim, do carisma e do pensamento de Chiara Lubich, perscrutando nesses os elementos antropológicos e a lógica relacional que sejam capazes de infundir a economia. Entendemos que, como realidade comunitária, o carisma engendra e fortalece, nas relações, a dinâmica do dom, sendo, assim, capaz de realocar a lógica instrumental para aquelas relações que são estritamente instrumentais. Por fim, apresentamos a Economia de

\footnotetext{
* Doutor em Psicologia pela Universidade de São Paulo, mestre em Teologia Fundamental pela Pontifícia Universidade Lateranense, mestre em Psicologia pela Universidade de São Paulo. É Professor adjunto no Programa de Pós-Graduação em Teologia da Pontifícia Universidade Católica do Paraná. Curitiba - PR, Brasil. marciovisconde@yahoo.com.br.

** Mestre em Teologia pela Pontifícia Universidade Católica do Paraná - PUC/PR, graduado em Sociologia pela Universidade de Brasília - UnB. Curitiba - PR, Brasil. cleitonssantana@ yahoo.com.br.
} 
Comunhão como exemplo concreto de realização econômica que busca estabelecer novas formas de pensar e agir na economia.

Palavras-chave: Dom; carisma; Chiara Lubich; Economia de Comunhão

\begin{abstract}
This study deals by the search for criteria and economic motivations that contrast with the predominant instrumental logic. Our theoretical trajectory will start from the distinction between formal and substantive economics, as enunciated by Karl Polanyi, going through the critique of utilitarian logic, arriving at the requirement to return to obsolete criteria, such as gift and reciprocity, present in charisms. Thus, we approach Chiara Lubich's charism by examining in these the anthropological elements and the relational logic capable of infusing the economy. As a community reality, the charism generates and strengthens in the relations the dynamics of the gift, and is thus able to reallocate the instrumental logic to those relations that are strictly instrumental. Finally, we present the Economy of Communion as a concrete example of economic achievement that seeks to establish new ways of thinking and acting in the economy.
\end{abstract}

Keywords: Gift; charism; Chiara Lubich; Economy of Comunion

\title{
1. Introdução
}

O desenvolvimento econômico do nosso tempo, marcado por contradições e incertezas, avanços tecnológicos e volatilidades de capitais, pujança e miséria, eficiência energética e degradação ambiental, acende questões éticas agudas e complexas. Responder àquilo que é suscitado por um tal desenvolvimento é uma das exigências postas pela pós-modernidade, época que parece ainda carente de respostas à altura dos grandes questionamentos desse tempo.

Ao olharmos o mundo contemporâneo, percebemos que os desafios não são de natureza técnica e econômica primordialmente, mas problemáticas de um outro espectro que se impõem não só à economia (enquanto ciência e enquanto esfera da vida social), mas à política, às artes, às ciências em geral e também à religião. O Papa Francisco continua a apontar que a crise econômica 
poderia ser uma oportunidade de revisão "dos critérios obsoletos que governam o mundo" (LS 189) e que as religiões podem oferecer princípios e critérios éticos que, em diálogo com a técnica e as ciências, apontem novos horizontes de desenvolvimento para as sociedades, em respeito ao ser humano e a toda a criação.

No presente artigo, partimos dos pressupostos da sociologia weberiana quanto à relação entre carisma e mudança social e, em uma perspectiva teológica, nos aproximamos do pensamento de Chiara Lubich, líder carismática fundadora do Movimento dos Focolares, perscrutando, no seu pensamento, os princípios hermenêuticos e econômicos que deram origem, a partir do Carisma difundido no movimento que fundou, ao projeto da Economia de Comunhão (EdC).

\section{Racionalidade, lógica e econômica e utilitarismo moderno}

Quando falamos de economia e política, quase sempre partimos de questões macroeconômicas ou de política institucional. O discurso acerca desses temas pode assumir um caráter pessimista. Corre-se também o risco de cair em uma visão idílica do passado (como se algum sistema político ou econômico já existente fosse melhor que o atual) ou nas metanarrativas de salvação política e econômica típicas de outros tempos.

A desarticulação da vida social, a geração de fluxos migratórios e a degradação humana em decorrência de sistemas econômicos e políticos injustos não são particularidades do nosso tempo. Podemos falar de economia em outros termos. Karl Polanyi é um autor que nos ajuda a falar da economia em termos de relações sociais, não somente como instituições e sistemas de produção. Na sua análise, embora todos os tipos de sociedade conhecidos sejam condicionados por fatores econômicos, somente a partir do século XIX é que a nossa civilização escolheu basear-se no lucro como justificativa do 
comportamento humano, tornando possível a existência de um mercado autorregulável ${ }^{1}$.

É justamente o princípio de autorregulação do mercado que significa, em outras palavras, a autonomia da economia em relação à sociedade, o que Polanyi aponta como problemático. Para ele, é preciso lembrar que "a economia do homem, como regra, está submersa em suas relações sociais"2. Isso significa que a ascensão da economia sobre essas relações, transformando-as em relações econômicas, tende a disseminar a lógica instrumental a todos os âmbitos da vida humana e a transformar, assim, o social no econômico e o ser humano de ser social a homo oeconomicus.

O pensamento de Polanyi precisa o uso do termo "economia" para que se possa compreender a distinção feita nos princípios que a regulam. $\mathrm{O}$ autor aponta que etimologicamente o termo traz dois significados distintos: um primeiro significado, que ele chama formal, e um segundo, que chama substantivo. $\mathrm{O}$ primeiro significado diz respeito às relações meio-fins, liga-se à ideia de escassez e de economizar. $\mathrm{O}$ aspecto substantivo diz respeito à relação do ser humano com a natureza e de como esse extrai do meio natural os recursos necessários à sua subsistência. Essa subsistência não está associada somente à sobrevivência corporal (alimento, abrigo), mas a toda gama de necessidades que o ser humano possa ter, materiais ou não, supríveis, no entanto, sempre por meios materiais.

Polanyi demonstra, assim, que a economia tem um significado substantivo completamente diverso da relação instrumental meio-fins, que foi o pensamento prevalente na Modernidade. Nesse pensamento, o pressuposto da ação é que, para se atingir um fim desejado, utiliza-se um meio material escasso. Assim, economia passa a ser sinônimo de ação de obtenção do máximo desejável com o mínimo de recurso disponível.

\footnotetext{
${ }^{1}$ POLANYI, Karl. A grande transformação: as origens da nossa época. Rio de Janeiro: Campus, 2000. Trad. Fanny Wrobel. p.18

${ }^{2}$ Ibidem, p.65
} 
O autor aponta ainda que, a partir do século XVIII, a teoria econômica passa a fundir os dois significados em um único conceito, em que o comportamento e a motivação típica do mercado, ou seja, a obtenção do lucro (maximização do ganho) por meio do uso de bens escassos, passa a ser compreendido como explicação universal do comportamento humano. A essa associação da economia em geral com sua forma particular de mercado, Polanyi chama de falácia economicista ${ }^{3}$.

Persiste, nos tempos hodiernos, a sobreposição da esfera econômica sobre as demais instâncias da vida, de modo que a política, a arte, as relações sociais em geral, a religião e os diversos campos do saber parecem assumir traços das relações contratuais de comércio e troca de mercadorias e o mercado tornou-se onipresente.

Paradoxalmente, no mercado, de onde as relações não contratuais quase foram excluídas, tornando-o o lugar das grandes corporações e dos grandes detentores de capital, como afirmava Polanyi, vimos emergir novas formas de organizações, seja de caráter local, seja de caráter transnacional, onde as motivações para a ação não são, primordialmente, de ordem utilitarista, mas da ordem da reciprocidade e do dom, aspectos que esse autor associava à economia substantiva.

O sociólogo Alain Caillé resume o atual estado do surgimento de novas formas de instituições econômicas no mundo contemporâneo, apontando o desenvolvimento do setor terciário, do voluntariado e do engajamento associativo como resultado da incapacidade do mercado e do estado seja em garantir sobrevivência material no mundo da pobreza, seja em responder aos novos problemas que surgem no mundo da riqueza. ${ }^{4} \mathrm{O}$ autor fala que essa incapacidade em responder às demandas da sociedade leva à necessidade de novas formas de solidariedade, além daquelas já existentes na família. Essa solidariedade, para ele, exprime-se institucionalmente com o

\footnotetext{
${ }^{3}$ POLANYI, Karl. A subsistência do homem e ensaios correlatos. Rio de Janeiro: Contraponto, 2012. Trad. Vera Ribeiro. p. 69

${ }^{4}$ CAILLÉ, Alain. Antropologia do dom: o terceiro paradigma. Petrópolis: Vozes, 2002. p. 141
} 
surgimento de cooperativas sociais, associações e atividades coletivas sem fins lucrativos, permeadas pela presença do dom.

Seja no pensamento de Polanyi, seja naquele de Caillé, registra-se uma crítica ao caráter utilitarista da lógica predominante no Mercado. Cada um, a seu modo, aponta também à emergência dessa crítica em formas institucionais, na tentativa de corrigir o predomínio da economia formal (para usar os termos de Polanyi) sobre a substantiva.

\section{Dom, Carisma e Economia}

No nosso entender, há uma crise no modelo de relações humanas prevalente na cultura contemporânea. As consequências dessa crise estão presentes na política e na economia, essas compreendidas como esferas de macro relações sociais. Dessas relações de caráter político e econômico, características fundamentais do ser relacional humano foram retiradas, restando somente a crueza dos trâmites burocráticos e a insípida segurança contratual que molda os relacionamentos sob a égide da formalidade. É a gaiola de ferro da burocracia, como diria Weber, a quem Fernandes faz alusão para dizer que é preciso "resgatar outros critérios de racionalidade que não sejam a instrumentalização e o economicismo", se quisermos sair do desequilíbrio socioambiental que o tecnicismo produziu.

Resgatar critérios em desuso e assumir responsabilidades pressupõem liberdade e motivação. Quanto à liberdade, Polanyi aponta que a sociedade de mercado também produziu liberdades que são um valor inquestionável, tal qual as liberdades civis de expressão, de associação, de consciência, etc., as quais devem ser preservadas. Mas motivações profundas, onde as encontramos? Que tipo de motivação pode alterar o modo de agir humano, produzir valores e reconduzir à economia parâmetros éticos, motivos outros que o lucro?

\footnotetext{
${ }^{5}$ FERNANDES, Valdir. A racionalização da vida como processo histórico: crítica à racionalidade econômica e ao industrialismo. Cadernos Ebape, v. 6, nº 3, Set. 2008, p. 19.
} 
Weber descortina para nós a existência de uma força social capaz de romper e criar tradições, modificar e restaurar religiões, arrebatar e formar seguidores, inculcar e difundir novas éticas, gerar e moldar comportamentos em um amplo espectro de atuação. Essa força é o carisma ${ }^{6}$. Importante notar, antes mesmo de entrar em questões conceituais, que carisma é dom. É gratia gratis data e, porque dom, está inscrito nas motivações não-instrumentais do agir, pressupõe gratuidade e, assim, contrasta com o utilitarismo moderno.

Luigino Bruni aponta que, na modernidade, a descoberta da subjetividade e da alteridade enquanto um "tu" com o qual o "eu" se relaciona esteve acompanhada de um certo medo decorrente dessa relação. Isso porque essa alteridade foi pensada sobretudo em termos negativos, como aquele que não sou eu, em que a ênfase está na negação e, não, na alteridade. Bruni defende a tese de que na modernidade o "homem encontra-se diante de um outro como ele mesmo, mas diferente de si, em que cada 'eu' representa para o outro 'eu', um 'não', um não-ser”"?

Admitindo que a relação com a alteridade traz subjacente um aspecto de negação, Bruni utiliza-se da metáfora bíblica da luta de Jacó com o anjo, na qual esse último fere o primeiro à medida que o abençoa, como metáfora de toda relação humana na qual há potencialmente o risco da ferida, sem a qual a benção não se faz presente. Com isso, Bruni está dizendo que as relações verdadeiramente humanas são aquelas cuja intensidade e proximidade admitem a ambiguidade do depender do outro para ser feliz, na forma de amizade e reciprocidade, ao mesmo tempo em que essas só existem na condição de liberdade do outro. Bruni afirma que o homem moderno viu somente o perigo, a "ferida" da relação com o outro e buscou defender-se dessa ferida, utilizando-se de mediações de caráter social.

A explicação de Bruni traz uma crítica à exclusão dos afetos e dos relacionamentos de reciprocidade (exclusão do dom) que a economia

\footnotetext{
${ }^{6}$ WEBER, Max. Economia e sociedade: fundamentos da sociologia compreensiva. Trad. Regis Barbosa e Karen Elsabe Barbosa. Brasília: Editora UnB, 2012. vol. 2, p. 323

${ }^{7}$ BRUNI, Luigino. A ferida do outro: economia e relações humanas. Abrigada: Cidade Nova, 2010. p. 32
} 
(enquanto prática e enquanto ciência) empreendeu. $\mathrm{O}$ autor aponta como prevaleceu a ideia de interesse na explicação das relações, tendo sido depreciadas as concepções de bondade e gratuidade na teoria liberal clássica. Findou-se, na perspectiva de Bruni, por teorizar uma economia sem alegria, sem reciprocidade e afeto; uma economia sem gratuidade, sem a charis de onde etimologicamente a primeira deriva, sem aquilo que dá alegria profunda aos seres humanos, e não somente experiências sensoriais agradáveis; uma economia sem carismas, visto que:

na modernidade a ferida do outro é sobretudo uma ferida de relação, uma incapacidade de se encontrar e de se abençoar na reciprocidade. Na pósmodernidade esta ferida espiritual e relacional mostra cada vez mais a sua dramaticidade. Estamos à espera de novos carismas (e se estivessem já presentes?) que, com um novo olhar, nos ajudem a ver bênçãos nestas feridas ${ }^{8}$.

A teorização econômica de Bruni nos conduz ao Carisma como possibilidade de introjetar, na esfera econômica, critérios substantivos que levem ao desenvolvimento humano. Bruni nos afirma que é impossível pensar no desenvolvimento econômico ocidental, desprezando o papel que os carismas desempenharam ${ }^{9}$.

Piero Coda nos dá os elementos fundamentais para a compreensão de carisma que adotamos neste trabalho. Seguindo a trilha de Hans Urs von Balthasar, Coda conceitua o carisma como sendo luz proveniente do Espírito que conduz os que a recebem a olhar e penetrar mais profundamente o centro da revelação dada em Jesus Cristo. Para Coda, graças aos carismas, os "olhos do coração e da mente" tornam-se capazes de ver mais longe, "alcançando novas e mais eficazes energias de vida e projetação histórica"10.

\footnotetext{
${ }^{8}$ Ibidem, p. 188

${ }^{9}$ Ibidem, p. 176

${ }^{10} \mathrm{CODA}$, Piero. Un carisma nella storia come sguardo dal centro. In: Carisma, storia, cultura: una lettura interdisciplinare del pensiero di Chiara Lubich. Roma: Città Nuova Editrice, 2014. p. 22, tradução nossa.
} 
No pensamento de Coda, o carisma é olhar contemplativo e cognoscitivo de Deus mesmo, mas é, ao mesmo tempo e a partir da centralidade de Deus, olhar transformador (e transformado) sobre o mundo, é projetação e engenhosidade de respostas que sejam adequadas às exigências e às vicissitudes do tempo. Importante notar, assim, a intrínseca coincidência temporal desse olhar para Deus e para o mundo.

O carisma, no entanto, não é uma experiência de natureza somente pessoal e que diga respeito à vida do indivíduo. Vemos, em nossos dias, uma tendência à subjetivação dos dons carismáticos, muitas vezes entendidos como dons pessoais para a santificação do crente. Em algumas comunidades cristãs, esses dons, notadamente aqueles de cura e línguas, não raro tomam as características de competências pessoais ou, ainda, são consumidos com o viés de autoajuda e cura da subjetividade. A história dos carismas nos ensina, porém, que, onde encontramos figuras carismáticas, encontramos frequentemente comunidades carismáticas que transformam aquilo que poderia ser interpretado como uma questão de natureza individual e quase biográfica em algo de natureza social.

Segundo Ciardi, é fundamental entender que o carisma suscita homens e mulheres "capazes de profecia" e de criar novas formas de vida cristã, dando vida a espiritualidades, ordens religiosas e movimentos. Para esse teólogo, embora dado a uma pessoa, o carisma adquire um caráter coletivo na medida em que envolve mais pessoas no mesmo ideal de vida, garantindo, assim, a perpetuação desse ideal no tempo ${ }^{11}$.

O caráter, por assim dizer, centrífugo do carisma transborda os limites da Igreja, não está direcionado a essa como se fossem apêndices departamentais de uma instituição, mas a enriquecem e adornam justamente pela ruptura das estreitezas que, por vezes, nela se apresentam. Voltam-se os carismas para a humanidade inteira e, por essa razão, edificam a Igreja, que é, como bem afirma Domenico Grasso, "não um edifício sem portas e janelas, finalizado a si mesmo, soberbo na sua beleza e autossuficiência, mas é toda

\footnotetext{
${ }^{11}$ CIARDI, Fabio. Carismi: Vangelo che si fa storia. Roma: Città Nuova, 2011, p. 28.
} 
voltada para fora de si para anunciar aquilo que Deus fez por ela e pode fazer por quantos respondam ao seu chamado"12.

É porque os limites da sua atuação e o horizonte que se coloca à sua frente são a humanidade inteira que o carisma adquire valência sociológica e força de transformação social, tanto e à medida que essa visão seja não só de um indivíduo, que ainda assim pode provocar enormes implicações sociais, mas quanto e à medida que essa visão se dissemine e se perpetue em formas institucionais.

Dialogam com a nossa conceituação de carisma as intuições apontadas por Luigino Bruni. Para esse economista, o dom carismático é sobretudo capacidade de ter um olhar diferente para a realidade circundante. É capacidade de ver "bênção" onde parece haver somente "ferida". Ou seja, é hermenêutica transformadora da vida, é olhar empreendedor, é acurada percepção das possibilidades de ação. É segundo esses termos que o autor pode afirmar que "não há desenvolvimento plenamente humano, e não há inovação social, sem os carismas"13.

Para Bruni, assim como para Weber, a história da humanidade está pontilhada desse tipo de experiência. Bruni, no entanto, reconhece que é no campo da economia civil onde as experiências carismáticas deixam sua marca mais evidente. Isto é, para o autor as marcas da ação dos carismas na história não estão somente na esfera religiosa, como se poderia imaginar, mas na esfera econômica mesma.

Reside nessa nova hermenêutica da realidade, com a capacidade de ver aquilo que não é evidente e reinterpretar a realidade, dando a ela um sentido diferente daquele que lhe é atribuído pelo senso comum, a capacidade de inovação dos carismas. Como realidade comunitária, o carisma engendra e fortalece nas relações a dinâmica do dom, sendo, assim, capaz de realocar a lógica instrumental para aquelas relações que são necessariamente instrumentais.

\footnotetext{
${ }^{12}$ GRASSO, Domenico. I Carismi nella Chiesa: teologia e storia. Brescia: Editrice Quereniana, 1982. tradução nossa.
}

${ }^{13}$ BRUNI, op. cit., p. 184 


\section{A ação social no carisma e no pensamento de Chiara Lubich}

A visão carismática de Chiara Lubich, com a qual imbuiu o Movimento dos Focolares e da qual a Economia de Comunhão é herdeira, é a de que uma espiritualidade, se vivida, tende a revolucionar tudo, da política à arte, da religião à diversão. Em um texto de forte teor místico, escrito na década de 50, no qual Lubich exprime a sua "visão" sobre a cidade de Roma, ela afirma:

Jesus deve ser ressuscitado na Cidade Eterna e inserido em toda parte. É a vida, a Vida completa. Não é somente um fato religioso... Separá-lo da vida integral do homem é uma heresia prática dos tempos de hoje, é sujeitar o homem a alguma coisa inferior a ele e banir Deus, que é Pai, para longe dos filhos.

Às vezes pensamos que o Evangelho não resolve todos os problemas humanos e traz somente o Reino de Deus entendido num sentido unicamente religioso. Não é bem assim. Certamente não é o Jesus histórico ou Jesus enquanto Cabeça do Corpo místico que resolve todos os problemas. Quem resolve é Jesus-nós, Jesus-eu, Jesus-tu... É Jesus no homem, naquele determinado homem - quando a sua Graça está nele - que constrói uma ponte, abre uma estrada [....$^{14}$

No pensamento de Chiara Lubich, toma corpo a ideia sinteticamente enunciada no excerto acima: que o evangelho não é um livro de espiritualidade etérea, mas um livro que diz respeito à vida concreta das pessoas, as quais, membros do corpo místico de Cristo, agem consequentemente a isso. Para ela, "Jesus-nós" é quem age e transforma o mundo, com o auxílio da Graça. Explicitar de antemão esse pensamento é imprescindível para compreender que Lubich busca fugir de dualidades, com a pretensão de suprimir a contraposição entre religião e vida profana, ou entre espiritualidade (vida espiritual) e vida social.

\footnotetext{
${ }^{14}$ LUBICH, Chiara. Ressurreição de Roma. ABBA, Revista de cultura. Vol. I, p. 9
} 
O aspecto hermenêutico fundamental do carisma de Chiara é o olhar todas as coisas a partir do Uno. Para ela, há uma unidade fundamental das coisas, algo que as unifica, sem anular suas diferenças. Mais que isso, no pensamento de Lubich, conforme aponta Giuseppe Zanghì, a unidade fundamental de todo o criado pressupõe as diferenças e a relação entre as coisas criadas, pois aquilo que as une (e também as diversifica) é o amor ${ }^{15}$.

O amor é, na visão carismática de Lubich, pressuposto ontológico da pluralidade e da unidade das coisas e das relações. Nos seus escritos, o caráter relacional não é prerrogativa humana, mas de todo o cosmo criado, onde cada coisa (mesmo as plantas, os rios) tem a sua razão de ser, o seu fundamento ontológico, na doação de si e na recepção do outro. Todas as coisas existentes estão em relação de amor, e essa relação é Deus mesmo, o Uno. Para Chiara Lubich, essa é a visão por excelência, a visão do Uno, da unidade subjacente a toda diversidade ${ }^{16}$.

Daqui extraímos dois pontos fundamentais da teia conceitual/prática do pensamento carismático que fundou, a partir do Movimento dos Focolares, um projeto econômico específico, a Economia de Comunhão. São estes: a relacionalidade intrínseca a tudo o que existe e a Unidade como pressuposto hermenêutico para a compreensão dessa relação.

A narrativa de Chiara, que acima reportamos, traz subjacente uma peculiar compreensão do sujeito da ação econômica. Esse não seria um indivíduo, nem mesmo um grupo anônimo. É antes um sujeito coletivo (Jesusnós), no qual individualidade e coletividade ou, em outras palavras, o uno e o múltiplo não estão em conflito nem em relação dialética, e no qual não há sobreposição nem anulação dos polos, mas distinção e unidade na pluralidadeunidade do sujeito.

\footnotetext{
${ }^{15}$ ZANGHÌ, Giuseppe Maria. Leggendo un carisma: Chiara Lubich e la cultura. Roma: Città Nuova editrice, 2013. p. 41

${ }^{16}$ LUBICH, Chiara. Paradiso di '49 in Il Patto del '49 nell'esperienza di Chiara Lubich: percorsi interdisciplinari. Roma: Città Nuova editrice, 2012. p 13
} 
Surge, do pensamento de Chiara Lubich, a noção de um sujeito social novo, que existe onde há uma relação de mutualidade estabelecida aos moldes de uma recíproca imanência das pessoas que se relacionam. Nessa relação, as pessoas já não são indivíduos nem formam um coletivo anônimo, mas, permanecendo elas mesmas, formam uma unidade coletiva, que é múltipla e compacta ao mesmo tempo. Isso se dá pela comunhão entre si e com Jesus. Ela mesma explicita isso com as seguintes palavras:

Como pactuamos a unidade, somos um, nos tornamos um único Jesus, filho no Filho; mas assim cada um de nós é Jesus. O único Jesus e muitos Jesus, tantos quantos somos, segundo a nossa específica personalidade sobrenatural em Jesus, que recebemos como dom do saber perder aquela (personalidade) meramente natural. Somente seremos Jesus distintos se formos Jesus unidos. É participação não individual - o que seria uma contradição em termos! mas coletiva, comunional, em Jesus, na vida da Trindade ${ }^{17}$.

Compreendemos, dessa maneira, o que significa o agir segundo o Evangelho no pensamento de Chiara. Significa agir tendo Jesus como modelo ético e, mais que imitá-lo, ser um outro Jesus, inserir-se na vida da Trindade por meio da Palavra, da Eucaristia e da relação de amor mútuo entre as pessoas na labuta diária de cada homem e mulher. Assim, esse homem e essa mulher já não são indivíduos que agem, mas homem-Jesus e mulher-Jesus, realidade coletiva que preserva a individualidade. Na ação ordinária, esse homem e essa mulher, ligados ontologicamente, são um sujeito coletivo que age.

A ação de cada pessoa não é, pois, ação de um indivíduo isolado, nem de uma classe ou de um sujeito jurídico-institucional, mas ação pessoal que denota participação em uma coletividade. É ação em comum, comunitária, mas que não necessita da manifestação coletiva para explicitá-la. É ação do sujeito em comunhão. A compreensão trazida por Lubich se insere na mais profunda e sublime eclesiologia de comunhão do Concílio Vaticano II, como

${ }^{17}$ LUBICH, Chiara apud CODA, Piero. Sobre a teologia que irrompe a partir do carisma da Unidade. ABBA, revista de cultura. Vol. I, ano 1998. Trad. José Maria de Almeida. p.39 
testemunhado pelo Papa Francisco em recente discurso. ${ }^{18} \mathrm{Na}$ experiência carismática de Chiara, a união com Deus é indissociável da comunhão de vida com os irmãos, no amor recíproco que os liga, e da comunhão sacramental, graça do Espírito que os transforma em outro Cristo. Inabitados pelo Espírito, os fiéis são fundidos na Igreja e nessa são chamados à comunhão trinitária (cf. LG 4). Lubich exprime-se de modo veemente na seguinte afirmação:

Tendo ele [Jesus] derramado em nossos corações o amor de Deus, por meio do Espírito Santo, permite-nos participar da mesma comunhão que existe entre Ele e o Pai. No seu testamento, Ele fala do relacionamento profundo entre as pessoas da Santíssima Trindade e deseja que os homens tenham um relacionamento iluminado por esta mesma comunhão. ${ }^{19}$

Essas palavras ecoam a afirmação conciliar do chamamento universal à comunhão no mistério da Igreja, sacramento e sinal da comunhão da humanidade com Deus (LG 1), "povo reunido na unidade do Pai e do Filho e do Espírito Santo" (LG 4). Essa Ressonância remete à dimensão Pneumatológica da Constituição da Igreja na e pelo Espírito. O carisma expresso por Lubich e reconhecido pelo Magistério é testemunha de um dos modos com o qual esse mesmo Espírito "rejuvenesce a Igreja" (LG 4).

Sem restringi-lo ao âmbito da Igreja, o carisma de Chiara Lubich propõe um transbordamento do princípio da comunhão para as demais esferas da vida humana (além da religiosa), colocando-o como fonte da relação e como dado antropológico fundamental. Destarte, a comunhão figuraria como critério e valor econômicos. Essa concepção antropológica subjacente ao pensamento de Lubich dialoga seja com a concepção econômica presente em Polanyi, seja com a Antropologia desenvolvida por Allain Caillè, seja com o Magistério recente da Igreja Católica.

\footnotetext{
18 Visita do Papa Francisco a Loppiano, em 10/05/2018. Disponível em <http://w2.vatican.va/content/francesco/pt/speeches/2018/may/documents/papafrancesco_20180510_visita-loppiano-focolari.html>. Acessado pela última vez em 29/05/2018.

19 LUBICH, Chiara. O sim do homem a Deus. São Paulo: Editora Cidade Nova, 1981.
} 
Dialoga com Polanyi quando se fala de economia em um sentido amplo. Para ambos, as relações econômicas estão além da relação utilitarista predominante no mercado. Polanyi nos ajuda a compreender que aquilo que se descreve como problema de natureza econômica, tal qual a desigualdade social, que deveria ser resolvido segundo pressupostos econômicos, é, na verdade, um problema social. Sendo assim, não encontra solução, primordialmente, na esfera econômica da vida social, mas nas relações sociais estabelecidas, das quais a economia é parte integrante.

Permeado pela Doutrina Social católica, o pensamento de Lubich encontra naquela uma peculiar ressonância, vista, por exemplo, na encíclica Caritas in Veritate de Bento XVI, embora aponte o Estado democrático como fundamental para regular o mercado e evitar os desequilíbrios e aposte na constituição de uma rede de instituições sociais, agindo subsidiariamente ao Estado, com fins à promoção de um desenvolvimento integral. Indica a pessoa humana e sua iniciativa livre, responsável e solidária como promotora de desenvolvimento.

Essa ação pessoal é possível, na visão de Bento XVI, não por causa do domínio dos saberes e das técnicas, mas, sem excluí-los, é possível quando motivada pelo Amor na verdade (Caritas in Veritate), por um "amor rico de inteligência e [uma] inteligência cheia de amor” (CV 30). Essa proposição exige, do ponto de vista do pensamento social, abertura interdisciplinar e respeito às epistemologias próprias de cada saber. Porém, encontra, na Teologia, lugar epistemológico em virtude da sua "vocação" a uma visão holística, não-fragmentária do ser humano. Pensar o Amor, como concebe Lubich e como defende o Papa, como motivador da ação só é possível, do ponto de vista de uma teoria da ação social, se se pensa o dom como princípio criador do laço social presente inclusive na economia.

A experiência carismática de Chiara nos adverte, pois, que, antes de falar de economia como sinônimo de relações de troca, é preciso falar de relações, daquilo que ontologicamente constitui o ser humano: suas relações, das quais gratuidade e doação, abertura e recepção, unidade, alteridade e transcendência são os atributos fundamentais. É nessas relações, da qual a 
comunhão é princípio constituinte, que repousa a possibilidade de estabelecimento de critérios econômicos além daqueles instrumentais.

A partir da hermenêutica carismática em que a Economia de Comunhão finca suas raízes, a economia passa a ter um outro centro e passa a ter outro significado e lógica de pensamento. Saem o estado, o mercado, a produção e o consumo e aparecem o ser humano e a relação interpessoal, cujo atributo característico é a comunhão. Homem e relações passam a ocupar o centro da economia, ao menos enquanto possibilidade teórica e interpretativa, rompendo com a tradição moderna de conceituar/praticar uma economia longe da vida concreta, mediada por instituições e ancorada em um tipo de relação contratual-instrumental.

\section{O exemplo da Economia de Comunhão (EdC)}

Sinteticamente, definimos a Economia de Comunhão como uma rede de pessoas e instituições comprometidas com a superação da desigualdade social a partir do paradigma antropológico cristão da comunhão, esta compreendida como princípio, meio e fim da própria atividade econômica empresarial. Esse projeto tem dimensões assentadas na prática da atividade empresarial, em estudos acadêmicos, em uma dimensão espiritual e em uma ampla rede de relacionamentos interpessoais.

A Economia de Comunhão emerge no caldeirão cultural e religioso no qual vivemos, onde as rupturas e as continuidades com aquilo que é moderno se conectam em arranjos sui generis. Nasceu no seio das comunidades dos Focolares no início da década de 90 e traz consigo uma concepção de empresa em que essa é tida como um lugar de relações de reciprocidade, capaz de promover uma intervenção social que se ancora na noção de promoção da autonomia e emancipação dos sujeitos.

A empresa, ao se associar ao projeto de Economia de Comunhão, compromete-se a buscar uma nova forma de gestão e de atuação no mercado, pautando suas ações não somente na busca do lucro, que permanece como um 
dos fins da atividade empresarial, mas na geração e distribuição de riqueza a todos os envolvidos na atividade. $\mathrm{O}$ fim empresarial não seria tanto produzir valor econômico a ser apropriado por um indivíduo, mas gerar comunhão, manifestada na organização mesma da empresa (comunidade de reciprocidade e dom) e na distribuição dos bens, sinal concreto dessa comunhão.

Concretamente a empresa é estimulada a pôr em comum (partilhar) os seus lucros com os pobres e o realiza por meio de projetos de superação de situações de vulnerabilidade social, atualmente geridos por uma associação nacional. Nas comunidades dos Focolares, os pobres são pessoas identificadas geralmente entre pessoas vinculadas às empresas ou, ainda, pessoas sem vínculos com o Movimento ou com alguma empresa de EdC, mas ligadas a alguém que participa do projeto.

Trata-se, portanto, de um modelo distributivo que está centrado na rede de relações que a comunidade empresarial ou religiosa cria e mantém. A própria empresa está submergida, de algum modo, nessa rede de relações, evocando, assim, o que assevera Polanyi quanto ao lugar próprio da economia, que o livre mercado sobrepôs.

A EdC associa elementos culturais da modernidade capitalista, notadamente a empresa, com elementos culturais pré-capitalistas, como as relações de reciprocidade e gratuidade e a vida comunitária de relações estreitas permeadas de afeto. Atribui, assim, à interioridade humana, lugar de liberdade criativa, papel motor da mudança social, em que o homem e a mulher espiritual, carismática, não têm relaxados os seus deveres de cidadania e participação na vida social, mas reforçados pelo dever ético que se lhes impõe de ser, por primeiro, sinal profético de uma humanidade nova.

Podemos, por isso, compreender qual a dimensão místico-espiritual, quais as consequências políticas e econômicas e, ainda, qual a valência sociológica enquanto explicitação de um princípio de teoria da ação, contida em uma das afirmações mais categóricas de Lubich acerca do agir econômico a ser seguido na Economia de Comunhão: "Exige-se mais igualdade, mais solidariedade, acima de tudo uma distribuição mais justa dos bens. É claro que 
os bens não se movem nem caminham sozinhos. São os corações que devem se mobilizar e viver a comunhão!"20

A perspectiva que Lubich imprime ao movimento que funda e ao projeto econômico que dele resulta é a de um ethos da responsabilidade pessoal que reclama não só conversão e engajamento em relações interpessoais pautadas no agir agápico, gratuitas e livres, mas também ampliação dessas a níveis institucionais, tais como a política e a empresa. Sendo vista inserida no mercado, a empresa parte da transformação de si, passa pelas instituições nas quais os sujeitos estão inseridos, e transforma a sociedade.

\section{Considerações finais}

O percurso teórico que fizemos e o mergulho no pensamento de Chiara Lubich nos apontam que um carisma traz consigo a capacidade de gerar empreendimentos econômicos, não por infundir uma cultura utilitarista, mas, sim, por radicar o sujeito aderente ao carisma em relações sociais fortes, das quais podem emergir instituições econômicas em que o princípio do lucro e a lógica utilitária estão regulados pelas exigências morais dessas mesmas relações.

"As exigências do amor não contradizem as da razão" (CV 30). Por isso mesmo, Chiara Lubich, ao fundar a EdC, indica que são necessários empresários que sejam expert no que fazem, ou seja, que conheçam a atividade empresarial e mobilizem esses mesmos conhecimentos (que incluem técnicas de gestão, modos de produção, estratégias de venda, conhecimentos em logística e toda a gama de conhecimentos técnicos necessários a uma bem sucedida atividade empresarial atuante no mercado) para a solução ou, ao menos, o enfrentamento do problema da desigualdade. A exigência é, enfim, que o empresário, inspirado pelo carisma, esteja alinhavado na tessitura das redes sociais que o carisma constrói.

\footnotetext{
${ }^{20}$ LUBICH, Chiara. As religiōes e a paz. Disponível em: http://www.centrochiaralubich.org/pt/documentos/textos/146scritto-pt/2242-as-religioes-e-a-paz.html. Acesso em: 08/06/2003
} 
Depreendemos que tal concepção é indissociável da "antropologia de comunhão" que Chiara Lubich esboçou. Com a linguagem que lhe era característica, Chiara repropôs o conceito de Pessoa, em detrimento daquele de indivíduo, fruto da experiência mística em que essa linguagem se origina, conforme a nossa investigação histórica nos demonstrou.

A mentalidade desenvolvida e difundida no seio dos Focolares é aquela que concebe a pessoa humana como um ser para a comunhão, preconizando que a realização humana, inclusive econômica, dá-se nas relações interpessoais, possível pela doação de si e recepção do outro (no dom), no estabelecimento do vínculo social da comunhão e da unidade. Essa unidade pressupõe o plural e prescinde da liberdade e da gratuidade do dom de si, que exige, sem esperar, a correspondência do outro. Em outras palavras, impõe a obrigatoriedade moral da reciprocidade, mas não depende dessa para que o dom seja realizado.

Está aqui, portanto, aquilo que rastreamos como sendo o fundamento da EdC em termos de princípios, aquilo que é a hermenêutica própria do carisma de Chiara Lubich. Esse é o princípio da comunhão, que pode ser descrito como um movimento que se dá no duplo sentido de sair de si (o sentido centrífugo de abrir-se) e do acolher em si (o sentido centrípeto do receber e fazer próprio), um movimento que é cada vez mais externo, até abraçar o cosmo, passando pelas pessoas e a terra inteira, e cada vez mais estreito, na consumação daquilo que é o carisma em si, a unidade.

\section{Referências}

BRUNI, Luigino. A ferida do outro: Economia e relações humanas. Abrigada: Editora Cidade Nova, 2010.

BENTO XVI. Carta encíclica Caritas in Veritate, sobre o desenvolvimento humano integral na Caridade e na Verdade.

CODA, Piero. Sobre a teologia que irrompe a partir do carisma da Unidade. ABBA, revista de cultura. Vol. I, ano 1998. Trad. José Maria de Almeida. 
CODA, Piero. Un carisma nella storia come sguardo dal centro. In: Carisma, storia, cultura: una lettura interdisciplinare del pensiero di Chiara Lubich. Roma: Città Nuova Editrice, 2014.

CAILLÉ, Alain. Antropologia do dom: o terceiro paradigma. Petrópolis: Vozes, 2002.

CIARDI, Fabio. Carismi: vangelo che si fa storia. Roma: Città Nuova, 2011.

CONSTITUIÇÃO DOGMÁTICA LUMEM GENTIUM. In: Compêndio do Vaticano II: constituições, decretos, declarações. $31^{\text {a }}$ edição. Editora Vozes: Petrópolis, 2016.

FERNANDES, Valdir. A racionalização da vida como processo histórico: crítica à racionalidade econômica e ao industrialismo. Cadernos Ebape. v. 6, $\mathrm{n}^{\mathrm{o}}$ 3, Set. 2008.

GRASSO, Domenico. I Carismi nella Chiesa: teologia e storia. Brescia: Editrice Quereniana, 1982.

LUBICH, Chiara. O sim do homem a Deus. São Paulo: Editora Cidade Nova, 1981.

LUBICH, Chiara. Paradiso di '49 in Il Patto del '49 nell'esperienza di Chiara Lubich: percorsi interdisciplinari. Roma: Città Nuova editrice, 2012.

LUBICH, Chiara. Ressurreição de Roma. ABBA, revista de cultura. Vol. I, 1998.

LUBICH, Chiara. As religiões $e$ a paz. Disponível em: http://www.centrochiaralubich.org/pt/documentos/textos/146scritto-pt/2242-as-religioes-e-a-paz.html. Acesso em: 08/06/2003.

POLANYI, Karl. A grande transformação: as origens da nossa época. Rio de Janeiro: Campus, 2000. Trad. Fanny Wrobel.

POLANYI, Karl. A subsistência do homem e ensaios correlatos. Trad. Vera Ribeiro. Rio de Janeiro: Contraponto, 2012.

WEBER, Max. Economia e sociedade: fundamentos da sociologia compreensiva. Trad. Regis Barbosa e Karen Elsabe Barbosa. Brasília: Universidade de Brasília, 2012. vol. 2.

ZANGHÌ, Giuseppe Maria. Leggendo un carisma: Chiara Lubich e la cultura. Roma: Città Nuova editrice, 2013.

Recebido em: 31/07/2018

Aprovado em: 07/06/2019 